\title{
Editorial for SI - Critically exploring co-production
}

When Raymond Williams published Keywords in 1976, it preceded a much earlier fascination he had with the relationship between culture, language and social change. This special issue, 'Critically Exploring Co-production' is of a similar vein. The collection of articles seeks to explore what the 'culture' of co-production has become. These articles discuss critical encounters whereby the "tones and rhythms, meanings [of co-production] are offered, felt for, tested, confirmed, asserted, qualified, changed” (Williams, 1976 p. 11). Co-production, similar to how Williams compiled Keywords, involves a set of words which are connected historically and intellectually - words like community, democracy and radical. Across the set of articles, co-production is put into practice in a range of contexts. In doing so, the initial heady excitement that such approaches could hatch new forms of knowledge production, give way to more critical and sober reflections on the limits of co-produced research.

In 2019, a conference on co-production [1] was co-hosted by the Manchester Centre for Youth Studies, the Education and Social Research Institute and the Faculty of Health, Psychology and Social Care at Manchester Metropolitan University. The ideas that led to this special issue emerged through discussions from participants and covered topics such as micro-socialities (Rogaly, 2016), the need to pay careful attention to complex processes (Perry and Atherton, 2017) and the potential of co-produced research for a more democratic and hopeful world. This special issue continues the dialogue by acknowledging the growing critique of co-produced research practices while hopefully and imaginatively attuning to our research practice to reimagine a world in process (Duggan, 2021).

Co-production promised to extend agency to others outside the academy and elite institutions and give them an equal place in how knowledge is produced. It promised to empower and equalise power relations (Beebeejaun et al., 2014) contribute to social change (Banks et al., 2018; Perry and Atherton, 2017) and enable those outside the academy to become actively involved throughout the research process as full beneficiaries (Liddiard et al., 2019). Aspirations were for multi-sector, multi-disciplinary collaborations to forge new understandings of how lives are lived, meanings are made and so how research might better impact policies to further social justice. Scientific expertise as the only legitimate form of knowledge was firmly swept off its perch. Mantras behind co-production were that community members, children or marginalised groups were to be heard and their knowledge counted as equal beside that of scientists and experts. The Connected Communities Programme (Facer and Pahl, 2017) was a good example of how the scientific community could engage with community-university partnerships to experiment and legitimise different means of knowledge production often referred to as living knowledge (Facer and Enright, 2016).

However, co-production has its limits within the neoliberal university. Bell and Pahl (2018) described the "cramped space" of co-production being constrained by issues around how funding and publications are ordered and distributed within academia. Genuine co-production, involving the writing of grant proposals with, not on communities, and co-writing which acknowledges and respects community knowledge, is often compromised by forces outside the control of well-meaning teams. Formal processes which dominate universities limit organic participation meaning that the process can become contrived (Malone and Hartung, 2010; Fox, 2013). The performative culture of academia constrains the time needed to nurture relationships especially with those who have undergone successive silencing and harm (Enright et al., 2016). Despite this, the question of whose knowledge counts and why has been questioned within these processes (Campbell et al., 2018).

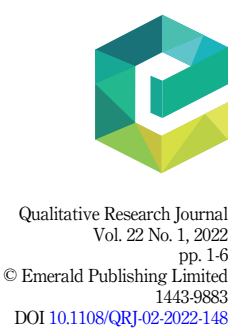


QRJ

22,1

\section{2}

Each paper illuminates limitations to co-production by making the effects of power visible. Authors grapple with the problem that we cannot flatten hierarchies to enable those involved an equal, yet different voice, because we all operate within capitalist and colonial frames. Some papers reveal the effects and affects of unexpected actants. New actants turn out to be materials such as art equipment, artefacts, visual images, sounds and new technologies. Authors recognise the way institutional structures seep into carefully crafted co-produced spaces as uninvited guests. They write of undertaking co-production as a journey that proved to be challenging, destabilising and troubling yet always highly generative. We hear calls to be open to the challenges hailed by voices other than academics, teachers or museum workers. Attuning to others requires accepting vulnerability, remaining open and foregoing privileged positions of knowing. In some accounts, we can feel the toll this can take on researchers, we sense the effort involved in being open and the hidden time that careful co-produced research demands. Authors sometimes agonise about audiences, asking - who am I writing this for? Especially given that most do not include as authors the people they co-created the knowledge with.

Papers also reveal unexpected insights: unexpected because as a research method co-production embraces life rather than bracketing it out, neutralising or controlling it. When researchers accept they are part of the dynamic swirl of life and begin to genuinely make this part of the process, they realise that the lively affordances of the universe are not within the already "known". Some manage to surf, improvise and intuit with lively forces and learn to embrace contingency, and this is when research really starts to come alive. Co-production is dangerous and generative research. Practices can sediment back into old familiarities or they can become the means to imagine different futures; different worlding (Manning, 2013). Co-productive research requires enormous care, a great deal of craft and craftiness, humility and bravery.

A number of papers approach the problems inherent in co-production head on and proceed to show glimmerings of possibility and creativity. Some demonstrate ingenious moves and processes of making that fleetingly escape dominant capitalist and colonial framings. While most papers offer critiques of co-production as a research approach, this does not mean that any of the authors wish to abandon it, yet each highlights elements that enable and restrict co-produced knowledge. The field of co-productive research is developing creative ways to include marginalised groups such as children, for example, and novel ways to share and communicate emergent, hybrid knowledge forms. Yet, public institutions such as museums, schools and universities, and the global corporations that design and provide virtual platforms come already saturated with monetary, colonial and capitalist weight, which means that the spaces of participation are never neutral. Yet, what is inspiring about these papers is that they widen the purview of who the players are in any collaborative research endeavour by making visible the post-human agency of space, sound, visual art and all kinds of matter revealing matter's potential to support us to imagine doing research otherwise.

Nash and colleagues bring to our attention the playful agency of open source digital code built in "processing 3" to disrupt research findings. They draw attention to the agency of digital codes, physical materials and making to disrupt the usual narratives of research findings from a network investigating children's virtual reality experiences in Japan and the UK. Grounded in the radical tradition of artists' books as forms "constantly bordering on otherness", the authors take us on a thought-provoking journey of how the affordances and properties of media such as artists' books and zines include hybridity and mobility to stretch the meaning of research as they play with "technologies of enchantment" to perform findings in novel ways.

While Nash and colleagues find the agency of digital technologies generative, Burkholder and colleagues explore the dangers and potentials of archiving artworks as a form of activism. 2SLGBTQ + participants were supported to fashion artefacts such as collages, zines and images of DIY facemasks as traces of their feelings and experiences. The researchers sent participants instructions on how to create artefacts at home or in their 
private spaces enabling participation at a distance during COVID-19 conditions. The paper focuses on participants' capacities to negotiate what they wished to display and not display in digital archives. Digital archives had the potential to open their work to new publics in Canada and beyond. The archives were stored on digital platforms such as Facebook, Twitter and Instagram and because they are designed and owned by a global corporation, algorithmic power could potentially appropriate queer activism for commercial purposes. The authors explore the challenges of arts-based digital archives and what participants chose to include and exclude while co-producing digital activism.

Noble and Wallis set out to challenge existing structures and knowledge hierarchies in a bid to make a university museum more democratic. Museum educators, artists and women from the community worked together to create playgroup activities for young children from two local nurseries. They devised drawing activities to enable children to express themselves within the museum space. The way children intra-acted (Barad, 2007) with large pieces of paper, crayons and stories while lying on the floor incited reflections. However, their embodied pedagogic approach was not made explicit to all participants. One nursery head teacher found the approach challenged her pedagogic norms and was inspired to change her practice. Yet, some playgroup practitioners found the approach inappropriate. Their disquiet made some hidden assumptions underlying the museum educators' pedagogy visible. For some playgroup practitioners, free embodied expression seemed to reinforce the elitism associated with a high status museum. The authors reflect on their co-produced practice and recognising they had not made their pedagogic approach an explicit part of their dialogues with local playgroup workers revealing how much care is required to genuinely include diverse groups.

While Noble and Wallis came to realise the effects of their unexamined assumptions while inviting others to co-produce research with them, Kill describes other revelations while researching in a museum setting. Her journey from initial optimism in the ideals of co-productive research to transform practice shifted to a mature realism when life entered her research in the form of the COVID-19 pandemic. Kill describes how her optimism was ruptured when museum officials closed access to the building where she was to work with youth participants. In developing a more nuanced view, she calls on Berlant's Cruel Optimism (2011) as a resourceful means for disrupting unconscious attachments to ideals. Her heartfelt account demonstrates how underlying unequal power relations between museum workers and youth participants were suddenly exposed during a global emergency making us aware that co-production is provisional and constituted by many forces such as hidden affects, dynamic change and fragmented practices.

Like Kill, Marston describes her doctoral study. Her account tells of setting up a co-productive research workshop with young people to explore the tricky topic of digital sexual relationships by focussing on the body in activities using art materials. This time the hidden institutional force is that of the school. School-based peer group hierarchical relationships interfered with what she hoped to do in the workshops. She draws attention to the agency of art materials to enable expression. Yet, at times Marston found herself having to actively intervene to keep the workshops safe from peer group hierarchies to enable the creative work to continue. She was forced to intervene to hold institutional forces at bay, both curtailing and facilitating the young people's expression, complicating the notion of equality in co-produced research in school settings.

Cooper and Jones' paper continues the theme of institutional power as an unavoidable force in co-produced research. They describe a small-scale university funded impact project, which aimed to co-produce research with students on loneliness during the COVID-19 pandemic in England. A series of workshops, research meetings and mixed method journaling were orchestrated. While the activities brought students together and enabled participants to discover the informal support students created to care for one another, it also revealed the 
problematic nature of what was found. Some elements of the University did not want the findings published in full. The authors attribute this to the ongoing marketisation of Higher Education (HE), pointing to the limits of co-producing research when students' views clash with institutional concerns over reputation and public image. They call for academics and $\mathrm{HE}$ leaders to open themselves to vulnerability in order to recognise how structures or lack of them actively perpetuate loneliness for students. The paper points to the problem of where coproduced knowledge goes. Sometimes it remains limited to the confines of a project having little impact, challenging the potential of co-productive research to transform institutional practices.

Eseonu and Duggan's paper exposes limiting points by asking who can participate legitimately in co-produced research. Eseonu (Black British African) enters into an extended dialogue with Duggan (White British) about who can lead on an Afrofuturism research project with young people if funded. The dialogue explores cultural appropriation and whether or not a White British person can have a legitimate role in a project co-produced with Black and Afro Diasporic communities using speculative and imaginative practices to generate "other stories" (Dery, 1994, p. 738). Duggan explains that he had hoped to re-imagine co-production through Afrofuturism, not to become an Afrofuturist. They discuss who owns the knowledge; knowledge created through Black rituals and practices largely to bypass the racist, colonial institutional norms of academic knowledge production. They come to the realisation that Duggan cannot lead an Afrofuturism project aimed at supporting oppressed Black communities to reimagine the place where they live, as it would involve cultural appropriation. Recognising he, as a White man, does not have an equal place to start to coproduce with others signals a limiting point to co-production. Eseonu suggests the way forward is not as simple as replacing White academics with Black academics. Instead, we are challenged to think in more historically and politically nuanced ways. Eseonu and Duggan propose that academics, artists and activists can work across culture if the research is given time, great care is taken in negotiations and if there is a non-trivial rationale. They start this process by making Esenou the first named author on their joint paper. Their brave dialogue performs the care required to undertake co-productive research.

If Esenou's paper takes co-production to its existential limit, Renold and Ivinson's paper describes what it takes to live co-produced research as activism over time as an ever-changing problem space. Situated in the ex-mining valleys of south Wales, their paper is based on over a decade of work in the ex-mining valleys of south Wales with young people, artists, schools and policymakers. They describe a slow co-production researching Relationship and Sexuality Education (RSE) in Wales which centres dartaphacts (mixing data, art and act/ivism). They call on Manning's (2016) notion of art-as-way, a passage, a continuous forming and remoulding of ideas in the making to keep traces of the young participants' experiences moving through time as dartaphacts. Some dartaphacts are helped on their way by researchers, artists and the young people and others gather affects in unanticipated ways. The paper hints that the only way to stay true to the young people's experiences of relationships is to dodge, shape shaft, be vigilant, anticipate and surf the many unanticipated waves of opportunity suggesting that co-produced post-human praxis is one of problem-surfacing. They show that some affects had the power to move politicians to act in expansive ways while others attracted internet tolls that periodically closed the research down. While they show tangible gains, the dexterity required to work like this comes over as palpably exhausting.

It is noteworthy that art processes and artefacts have become central to co-production. Across all the papers, art is more than a player in co-production; it is a means of jarring the power blocks researchers and participants are entangled with. Art practices and materials enable dynamic formations of hybrid, fragmented, mixed and generative modes of expressions through which ideas are made present, challenged, contested, imagined and redirected. Art-making practices seem to enable a pre-personal, non-conscious, collective humanity to carry on living and breathing. Maybe the coming of age of co-productive 
research involves a full and wholesome recognition of the power of art to move, to escape institutional capture, to set free and undo what institutional modes of knowledge hold together.

Yet in this mature phase of co-productive research, we have to acknowledge that some groups continue to be excluded by specific kinds of artistic (pedagogic) approaches, institutional spaces and modalities. What comes to attention in co-productive research involves agential cuts (Barad, 2007) that always involve issues of in/justice and in/equity where "matters of concern and matters of care are shot through with one another" (Barad in Kleinman, 2012, p. 69). Once a research approach encompasses life, it is somewhat serendipitous whether events move into collapse and chaos or whether ways can be found to keep participants' feelings and experiences travelling.

Maybe the trick is to recognise co-production as always on the move, throwing up new problems. Arts-informed practices enable emergent problems to be recognised, to shape shift and transform not once but continuously. With dexterity, care and creativity co-production enables participation as on-going activism that carries on because we learn to work the interstices in ever changing micro- and macro-political contexts. There is no doubt that co-produced research involves vigilance, careful listening, dialogue, negotiation, humility, vulnerability, effort, time, dexterity, emotional work and courage.

Harriet Rowley, Gabrielle Ivinson, James Duggan and Kate Pahl Education and Social Research Institute, Faculty of Health and Education, Manchester Metropolitan University, Manchester, UK

Note

1. https://www.mmu.ac.uk/sociology/about-us/events/detail/index.php?id $=10187$

\section{References}

Banks, S., Hart, A., Pahl, K. and Ward, P. (2018), "Co-producing research: a community development approach", in Banks, S., Hart, A., Pahl, K. and Ward, P. (Eds), Co-producing Research: A Community Development Approach, Policy Press, pp. 1-18.

Barad, K. (2007), Meeting the Universe Halfway: Quantum Physics and the Entanglement of Matter and Meaning, Duke University Press, Durham.

Beebeejaun, Y., Durose, C., Rees, J., Richardson, J. and Richardson, L. (2014), “Beyond text': exploring ethos and method in co-producing research with communities", Community Development Journal, Vol. 49 No. 1, pp. 37-53.

Bell, D. and Pahl, K. (2018), "Co-production: towards a utopian approach", International Journal of Social Research Methodology, Vol. 21 No. 1, pp. 105-117.

Berlant, L.G. (2011), Cruel Optimism, University Press, Durham.

Campbell, E., Pahl, K., Pente, E. and Rasool, Z. (2018), Re-Imagining Contested Communities: Connecting Rotherham through Research, Policy press, Bristol.

Dery, M. (1994), Flame Wars: the Discourse of Cyberculture, Duke University Press, Durham, NC and London.

Duggan, J.R. (2021), "The co-productive imagination: a creative, speculative and eventful approach to co-producing research", International Journal of Social Research Methodology, Vol. 24 No. 3, pp. 355-367.

Enright, B., Facer, K. and Larner, W. (2016), "Reframing co-production: gender, relational academic labour and the university", in Jupp, E., Pykett, J. and Smith, F.M. (Eds), Emotional States: Sites and Spaces of Affective Governance, Taylor \& Francis Group, pp. 36-51. 
QRJ 22,1

6

Facer, K. and Enright, B. (2016), Creating Living Knowledge: the Connected Communities Programme, Community University Relationships and the Participatory Turn in the Production of Knowledge, University of Bristol/AHRC Connected Communities.

Facer, K. and Pahl, K. (2017), "Introduction", in Facer, K. and Pahl, K. (Eds), Valuing Interdisciplinary Collaborative Research: Beyond Impact, Policy Press, pp. 1-21.

Fox, R. (2013), "Resisting participation: critiquing participatory research methodologies with young people", Journal of Youth Studies, Vol. 16 No. 8, pp. 986-999.

Kleinman, A. (2012), "'Intra-Actions' (interview of Karen Barad by Adam Kleinman)”, Mousse, Vol. 34, pp. $76-81$.

Liddiard, K., Runswick-Cole, K., Goodley, D., Whitney, S., Vogelmann, E. and Watts, L. (2019), “I was excited by the idea of a project that focuses on those unasked questions' co-producing disability research with disabled young people", Children and Society, Vol. 33 No. 2, pp. 154-167.

Malone, K. and Hartung, C. (2010), "Challenges of participatory practice with children", in PercySmith, B. and Thomas, N. (Eds), A Handbook of Children and Young People's Participation: Perspectives From Theory and Practice, Routledge, London, pp. 24-38.

Manning, E. (2013), Always More than One: Individuation's Dance, Duke University Press, Durham and London.

Manning, E. (2016), The Minor Gesture, Duke University Press, Durham and London.

Perry, B. and Atherton, M. (2017), "Beyond critique: the value of co-production in realising just cities?", Local Environment, Vol. 22 No. 1, pp. 36-51.

Rogaly, B. (2016), "Don't show the play at the football ground, nobody will come': the micro-sociality of co-produced research in an English provincial city", The Sociological Review, Vol. 64 No. 4, pp. $657-680$.

Williams, R. (1976), Keywords: A vocabulary of culture and society, Oxford University Press, New York. 